\title{
Overview of Complementary Feeding in Infants
}

\author{
Sridhar Kalyanasundaram ${ }^{1}$, Kandamaran Krishnamurthy ${ }^{2 *}$ and Vidya Kanamkote Narayanan ${ }^{3}$ \\ ${ }^{1}$ Consultant Neonatologist and head of the department, Zulekha Hospital, Dubai, UAE \\ ${ }^{2}$ Consultant Pediatric Intensivist, Queen Elizabeth Hospital, Barbados \\ ${ }^{3}$ Consultant Pediatrician, Mediclinic Parkview Hospital, Dubai, UAE
}

*Corresponding author: Kandamaran Krishnamurthy, Consultant Pediatric Intensivist, Queen Elizabeth Hospital, University of West Indies,Barbados

\section{ARTICLE INFO}

Received: 幽 September 29, 2020

Published: 慧 October 09, 2020

Citation: Kalyanasundaram S, Krishnamurthy K, Narayanan VK. Overview of Complementary Feeding in Infants. Biomed J Sci \& Tech Res 31(1)-2020. BJSTR. MS.ID.005045.

\section{ABSTRACT}

Complementary feeding, also known as weaning in common terms, is the introduction of foods other than milk in the infants' diet. It is a critical time in terms of the nutritional needs of these young and rapidly growing infants. There are many questions that arise in the minds of parents as well as the pediatricians who advise these parents on such issues. In this article, we have tried to summarize current knowledge on approach to this process-focusing on nutrition of infants from 4-6 months of age till around 2 years of age.

Keywords: Complementary feeding; Infant weaning; Breastfeeding; Infant led weaning; Infant nutrition

\section{Introduction}

Infant nutrition is a topic of great importance, and it is crucial to meet the requirements to ensure the babies reach their growth and developmental potential. Breastfeeding is the best nutrition for babies from the newborn period until 6 months of age. The WHO defines complementary feeding as the process starting when breast milk alone is no longer sufficient to meet the nutritional requirements of infants so that other foods and liquids are needed, along with breast milk [1]. In this article, we discuss an approach to complementary feeding, and we refer to it as the weaning process as well during this discussion.

\section{Why Do We Need Complementary Food?}

In the majority of the situations, breast milkalone is adequate (in exclusively breastfed infants) to meet the nutritional needs till the infant completes 6 months of age, and hence the recommendation to start after 6 months. We need additional foods to meet the increasing nutritional demands, as well as to improve satiety and meet the developmental needs of the infants, who enjoys sharing food with the family especially as they see them eat.

\section{When Do We Start Complementary Foods?}

As mentioned above, the WHO recommends exclusive breastfeeding until the end of 6 months of age [2], but this does not cover formula-fed or mixed fed babies. The evidence on which this recommendation was based on comparing weaning at 3-4 months compared with 6 months of age, and there was no significant difference in growth parameters, but a reduced risk of gastroenteritis in babies breastfed longer. Majority of the countries adopted this recommendation, but some offer more flexibility, to introduce the taste of other foods between 4-6 months. There is overall agreement that other foods should not be introduced before 4 months of age (17 weeks) as some studies have shown an increased risk of obesity in infants on formula or mixed feeding if solids introduced by 3 months of age. Delaying beyond 6 months ( 25 weeks) is not ideal as well as babies may be reluctant to progress on such foods and there is a risk of iron, iodine and zinc deficiencies developing in the infant. There is a wide variation in the breast milk composition, and there is a risk of iron deficiency if delayed cord clamping was not practised or if a baby was low birth weight (LBW) after weight [3].

In terms of gastrointestinal and renal maturation, babies are able to tolerate foods well after 4 months and their ability to cope is related to types of food ingested. In terms of neurologic maturity as well, most babies are ready between 4-6 months. The readiness can be assessed by cues including the infant's ability to sit with little or no help, to munch/chew and swallow soft, solid foods, to have 
lost the extrusion reflex (the projection of food from the mouth), and to demonstrate an interest in food especially when they watch other family members eat $[4,5]$. Consideration should be given to these factors as well, and though the majority of babies would benefit from waiting till 6 months to start weaning foods, there is a subgroup of babies (based on nutritional needs, social needs (like a working mother who could introduce one weaning food instead of starting formula, babies with reflux or low birth weight(LBW) babies where growth appears to be slower than expected based on birth centile etc.) where we could consider starting by 4-5 months of age. It is important to stress on delayed cord clamping in all babies as well as iron supplementation (starting at 2-3 months for LBW babies, and at 4-5 months for other breastfed babies). In preterm babies, we could start weaning by 6 months of age (chronologic age, not corrected age) and progress as per readiness.

\section{What Foods Do We Focus On?}

The main nutrients needed for infants include protein (for growth and repair), fat (for growth contribution and protein sparing, as well as neural development), carbohydrate (energy, neural maturation, multiple effects of glucose as a ready fuel source), iron, calcium and various other vitamins and minerals $[6,7]$. The idea is to provide balanced nutrition to the growing infant.

Current dietary guidelines for children promote the intake of a varied diet filled with healthy, nutrient-dense foods, comprising a wide range of vegetables and fruits, cereals (preferably whole grains), lean proteins, and dairy products. Cultural factors play a very important role, and the role of grandparents and elders and relatives in the family can't be discounted. Physicians have to be considerate and if any practice is not appropriate, they should explain in a sympathetic manner why that practice is not to be encouraged. An example is the introduction of honey with weaning foods in some cultures-we need to stress the importance of avoiding honey before 1 year of age due to the risk of infant botulism. We can introduce a variety of single-ingredient fruits, vegetables, grains, and meats, in any order, to allow for a baby to become accustomed to diverse flavours. Foods that are high in saturated fat, added sugars and added salt, which could displace the intake of healthier alternatives, should be limited.

As mentioned above, we should not give honey during the first year and whole milk is not to be used before 1 year of age (high protein and fat load, higher risk of iron deficiency). However, yoghurt, cheese, butter etc. can be given after 6 months of age. There should be no added salt or sugar in the food and sweetened beverages, including juices, should be avoided. We should avoid an excess of rice-based weaning due to possible arsenic load-we could use a mix of oats, wheat, other grains. To avoid excess gluten load, we can introduce wheat after 6 months as part of the above. The protein quality in meat, fish, eggs and legumes are good, and meals should have a good balance of these. Seafoods are a rich source of essential fatty acids and all these can be introduced anywhere from 6-9 months of age based on family preference.

Iron-fortified cereals are a good option, but it is ideal to give a mix of homemade and ready foods to avoid the child getting used to similar textures (home foods have good variation). Introducing progressively coarser textures from 8-9 months of age is important (like toast) and finger foods can be an encouraged-an element of baby-led weaning is appropriate.

\section{Food Allergy and Weaning}

Based on current evidence, there is no benefit from delaying the introduction of allergenic foods. Such foods can be introduced in culturally appropriate fashion any time after 4-6 months after nonallergenic foods are tolerated [8]. In infants at high risk of allergy, introducing peanuts in appropriate form between 4-6 months showed a lower risk of allergy to peanuts (LEAP study) [9]. Evidence similar to above for other potentially allergenic foods like egg and fish. Nuts like peanut butter in paste form or as a powder added to food can be introduced. There is no need to delay the introduction of egg, and it is important that egg and chicken are fully cooked to avoid the risk of salmonella. If introducing seafoods, it is better to consider one species at a time, so any allergy can be identified.

\section{Schedule of Feeding Solids along with Regular Milk Feeds}

While starting the introduction of solid foods, it is better to progress slowly with 2-3 spoonful twice a day and increase as baby tolerates. Breastfeeding should not reduce during this phase. Between 6 to 9 months, we could consider 3 solid feeds and once the volume of solid meal increases, we could reduce milk intake accordingly. Some individualization is important, and it is very important to avoid screen-time as an option to improve eating and pushing the baby to eat is likely to lead to picky eating. Parents should also be guided on appropriate dental care. Adequate intake of water is important and focus on water and fiber intake is important if the stool is noted to be hard. Dietary fiber is important for gut motility, avoiding constipation, promoting healthy gut microbiota (prebiotic effect) as well as improving satiety and avoiding overeating. Encouraging intake of fruits, vegetables, and legumes, recommending nut butters, as well as whole-grain cereals, will help improve fiber intake to achieve the recommended intake of $6-10 \mathrm{~g} / 1000 \mathrm{kcal}$ intake.

\section{Special Considerations for Vegetarians}

We should plan and guide carefully to get a balanced diet in vegetarian families. Soya, dairy foods, nuts and pulses will improve protein intake. Use of milk products (lacto-vegetarian) along with egg if possible (lacto-ovo vegetarian) will improve nutrition. Iron, zinc, calcium, B2, B12, Vitamin A and D, DHA and protein intake are all potential deficits. This deficit is relatively milder in lacto-ovo 
vegetarian [10]. Vegan families will face a deficit in all of these and careful supplementation, and parental education is important.

\section{Other Supplements}

It is important to continue vitamin D supplements along with a multivitamin during this period. Iron-rich foods should be focused on, including iron-fortified foods like infant cereals. Iron supplements should be started, as discussed above [10].

\section{Conclusion}

Weaning is a very important stage in the infant's development. Adequate support to the families, appropriate guidance encouraging holistic care (advice on foods to avoid, encouraging healthy practices with a focus on preventing picky eating, stress on dental hygiene) is very important and will contribute to the future health of this young generation.

\section{References}

1. (2002) World Health Organization WHO. Complementary Feeding. Report of the Global Consultation. Geneva, 10-13 December 2001. Summary of Guiding Principles.

2. Agostoni C, Decsi T, Fewtrell M, Goulet O (2008) ESPGHAN Committee on Nutrition. Complementary feeding: a commentary by the ESPGHAN Committee on Nutrition. J Pediatr Gastroenterol Nutr 46(1): 99-110.

3. Rafael Pérez-Escamilla, Gabriela S Buccini, Sofia Segura-Pérez, Ellen Piwoz (2019) Perspective: Should Exclusive Breastfeeding Still Be Recommended for 6 Months?, Advances in Nutrition 10(6): 931-943.

\section{ISSN: 2574-1241}

\section{DOI: 10.26717 /BJSTR.2020.31.005045}

Kandamaran Krishnamurthy. Biomed J Sci \& Tech Res

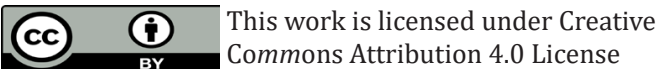

Submission Link: https://biomedres.us/submit-manuscript.php
4. Naylor AJ, Morrow A, editors (2001) Developmental Readiness of Normal Full Term Infants to Progress from Exclusive Breastfeeding to the Introduction of Complementary Foods. Reviews of the Relevant Literature Concerning Infant Immunologic, Gastrointestinal, Oral Motor and Maternal Reproductive and Lactational Development.

5. McNally J, Hugh-Jones S, Caton S, Vereijken C, Weenen H, et al. (2016) Communicating hunger and satiation in the first 2 years of life: a systematic review. Matern Child Nutr 12(2): 205-228.

6. Perkin MR, Logan K, Tseng A, Raji B, Ayis S, et al. (2016) Randomized trial of introduction of allergenic foods in breast-fed infants. $\mathrm{N}$ Engl J Med 374: 1733-1743.

7. Perkin MR, Logan K, Marrs T (2016) Enquiring early about tolerance (EAT) study: feasibility of an early allegenic food introduction regimen. J Allergy Clin Immunol 137: e86-88.

8. Ierodiakonou D, Garcia-Larsen V, Logan A, Groome A, Cunha S, et al. (2016) Timing of allergenic food introduction to the infant diet and risk of allergenic or autoimmune disease. A systematic review and metaanalysis. JAMA 316(11): 1181-1192.

9. Du Toit G, Sayre PH, Roberts G, Michelle L Sever, Kaitie Lawson M, et al. (2016) LEAP Study Team. Effect of avoidance on peanut allergy after early peanut consumption. N Engl J Med 374: 1435-43.

10. Fewtrell Mary, Bronsky Jiri, Campoy Cristina, Domellof Magnus, Embleton Nicholas, et al. (2017) Complementary Feeding: A Position Paper by the European Society for Paediatric Gastroenterology, Hepatology, and Nutrition (ESPGHAN) Committee on Nutrition. J Ped Gastroenterol Nut 64(1): 119-132.

$\begin{array}{ll}\text { BIOMEDICAL } & \text { Assets of Publishing with us } \\ \text { RESEARCHES } & \text { - Global archiving of articles } \\ & \text { - Immediate, unrestricted online access } \\ & \text { - Rigorous Peer Review Process } \\ & \text { - Authors Retain Copyrights }\end{array}$

